\title{
Geographic patterns of histone H1 allelic frequencies formed in the course of Pisum sativum L. (pea) cultivation
}

\author{
V. A. BERDNIKOV*, V. S. BOGDANOVA, S. M. ROZOV \& O. E. KOSTERIN \\ Institute of Cytology and Genetics, Russian Academy of Sciences, Siberian Division, SU-630090, Novosibirsk, C.I.S.
}

\begin{abstract}
An electrophoretic analysis of histone H1 of Pisum sativum L. was carried out using the collection of 883 accessions of cultivated peas originating from different regions of the Old World. The closely linked genes of five $\mathrm{H} 1$ subtypes $(2-6)$ form a cluster, the gene of subtype 1 being located on another chromosome. The fast allelic variant of subtype 1 was not observed to the north of the 44th parallel. The frequency of allele 1 of subtype 5 displays a latitudinal cline and is strongly correlated with the sum of aerial temperatures over the vegetational period. Allele 1 of subtype 6 prevails all over the Old World except Central Asia and China, where allele 3 predominates. From this area allele 3 frequency forms a declining gradient. Alleles of subtypes 2, 3 and 4 exhibit no regularities in their geographic patterns. The data indicate that alleles of $\mathrm{H} 1$ subtype 5 and, possibly, subtype 1 in garden pea were subjected to climatically-dependent natural selection under conditions of primitive farming (without conscious selection).
\end{abstract}

Keywords: electrophoretic polymorphism, geographic clines, histone H1, Pisum sativum quantitative trait genes.

\section{Introduction}

Quantitative trait genes are thought to be of primary importance for adaptive evolution because allelic substitutions in them make fine alterations to the phenotype (Mather \& Jinks, 1982). The quantitative trait genes with a high degree of pleiotropy are of great interest as they could be involved in various adaptational processes. It is reasonable to search for such genes among factors influencing the higher levels of gene regulation. From this point of view special attention should be paid to histone $\mathrm{H} 1$ genes. Histone $\mathrm{H} 1$ plays a key role in chromatin folding into higher-order structures (Thoma et al., 1979; Allan et al., 1980), and is thought to be a non-specific repressor of gene expression (Weintraub, 1985). Besides this, histone H1 is supposed to compete with specific gene activators for the regulatory sites of genes (Brown, 1984; Zlatanova, 1990). Recently it was proposed that histone $\mathrm{H} 1$ mediates the action of nuclear receptors as a participant in the induced regulatory cascade (Oikarinen, 1991). Therefore, alterations of molecular structure of histone $\mathrm{H} 1$ affecting its affinity to DNA or

*Correspondence. its interaction with other chromosomal proteins might result in changes in differential gene activity.

Histone $\mathrm{H} 1$, in contrast to conservative core histones, is highly variable in different organisms (Wells \& McBride, 1989). Moreover, H1 is frequently represented by several major subtypes, which may differ in strength of interaction with DNA (Cole, 1984) and differentially reduce the number of transcription initiation sites (Hannon et al., 1984). A preferential location of one of the $\mathrm{H} 1$ subtypes to certain bands of polytene chromosomes has been shown in Chironomus thummi (Mohr et al., 1989).

Our previous data suggest a possible role of $\mathrm{H} 1$ genes in adaptive evolution. The rate of molecular evolution of histone $\mathrm{H} 1$ appeared to correlate with the rate of taxonomic evolution in insects (Berdnikov et al., 1984). In a population of Vicia unijuga $\mathrm{A}$. Br., occupying a small territory, the allelic frequencies of one of the histone $\mathrm{H} 1$ subtypes exhibited a radial cline presumably formed under pressure of some humandependent factor (Berdnikov et al., 1992). A comparison of isogenic lines of garden pea that differ in histone $\mathrm{H} 1$ variants showed a mild effect of allelic substitutions in $\mathrm{H} 1$ genes over a number of quantitative traits (Bogdanova et al., 1989). 
In the present work we have attempted to obtain further evidence of susceptibility of $\mathrm{H} 1$ allelic variants to natural selection. For this purpose we studied the allelic composition of $\mathrm{H} 1$ genes in aboriginal forms of garden pea Pisum sativum L. not affected by conscious selection. This objective was chosen for two main advantages. First, the pea was domesticated some 9000-10,000 years ago (Zohary \& Hopf, 1973) and in the course of its cultivation has occupied a wide range of environments over a vast territory. Second, histone $\mathrm{H} 1$ of the pea is represented by a number of electrophoretic subtypes, each of them demonstrating allelic polymorphism that allowed genetic mapping of the corresponding genes. We revealed different geographic patterns for several $\mathrm{H} 1$ genes, suggesting that at least one of them was subjected to natural selection in the course of pea expansion over the Old World.

\section{Materials and methods}

\section{Isolation and electrophoresis of histone $\mathrm{HI}$}

Histone H1 was isolated by Johns' (1964) method with further modifications (Rozov et al., 1986): About 1-2 g of pea leaves were homogenized in $20 \mathrm{ml}$ of $0.15 \mathrm{M}$ $\mathrm{NaCl}$, the homogenate was filtered through two layers of gauze and centrifuged at $1500 \mathrm{~g}$ for $5 \mathrm{~min}$. Histone $\mathrm{H} 1$ was extracted by resuspending the pellet in $5 \mathrm{ml}$ of 5 per cent $\mathrm{HClO}_{4}$. After centrifugation the protein was recovered from the supernatant by adding six volumes of cold acetone and sulphuric acid to a concentration of $0.5 \mathrm{~m}$. The precipitated protein was centrifuged and then dissolved in $0.2 \mathrm{ml}$ of a medium containing $0.9 \mathrm{M}$ acetic acid, $8 \mathrm{~m}$ urea, and 15 per cent sucrose. The preparations were subjected to electrophoresis in long (up to $40 \mathrm{~cm}$ ) slabs of 15 per cent polyacrylamide $/ 0.5$ per cent $N, N^{\prime}$-methylenebisacrylamide gel containing $8 \mathrm{M}$ urea and $0.9 \mathrm{~m}$ acetic acid following a modification (Berdnikov \& Gorel, 1975) of Panyim and Chalkley'st(1969) method. After electrophoresis, the gels were stained in 0.01 per cent Coomassie R-250 in $0.9 \mathrm{M}$ acetic acid.

The resolution of slightly differing allelic variants of the slowest subtype was facilitated by cleavage of the histone $\mathrm{H} 1$ molecule at tyrosine residues by treating with $N$-bromosuccinimide $\left(1 \mathrm{mg} \mathrm{ml}{ }^{-1}\right)$ for $15 \mathrm{~min}$ (Sherod et al., 1974).

\section{Histone H1 electrophoretic spectrum}

Electrophoretic patterns of histone H1 in garden pea comprise, as a rule, seven subtypes (Fig. 1). The subtypes are denoted with numerals according to the increase in their electrophoretic mobility. Subtype 7 is detectable only in the growing parts of a plant, so it was excluded from our analysis.

Identification of the proteins in question as histone H1 is based on extractability from chromatin with 5 per cent perchloric acid and on the analysis of their molecular structure. These proteins contain an extremely large number of lysine residues (about 27-30 per cent as estimated by a method of incomplete succinylation) localized mostly in C-terminal part of the molecule that is characteristic for H1 (Belyaev \& Berdnikov, 1985). The cleavage with $\mathrm{N}$-bromosuccinimide and chymotrypsin (Rozov et al., 1986) revealed the aromatic residues (tyrosine and phenylalanine) to be located in positions characteristic for H1 histones (Wells \& McBride, 1989).

Each subtype can be represented by a number of electrophoretic variants. The variants of any subtype exhibit a mendelian segregation as being alleles of a single gene. The gene His 1 of subtype 1 was mapped on chromosome 5 (Rozov et al., 1986; Smirnova et al., 1990); other H1 genes were on chromosone 1. The genes of subtypes 2-6 are linked very closely forming a gene cluster His(2-6) (Belyaev \& Berdnikov, 1981), the gene of subtype 7 being located $33 \mathrm{cM}$ away (A. I. Belyaev, personal communication).

An allelic combination of genes of cluster His(2-6) attributed to a single chromosome will be referred to as a 'haplotype'. An allelic composition of a haplotype is designated by a haplotypic formula. As about 99 per cent of peas have the same variant of subtype 2 , its allelic state is not included in the formula, which is four symbols referring to subtypes 3-6. In accordance with the increase of their electrophoretic mobility the symbol of subtype 3 is placed first, that of subtype 4 is second, and so on. Each symbol is a digit corresponding to a certain allelic variant of the relevant subtype, the variants being numbered according to the increase in their electrophoretic mobility. For example, record 1221 means that the gene of the subtype 3 (the first position in the formula) is represented by the allele encoding the slowest variant, 1 , the gene of the subtype 4 (the second position), by the allele of the second slow variant, 2, and so on. Sometimes some H1 subtype is missing; in the absence of an electrophoretic band the subtype behaves as null allele, so it is denoted as 0 . The symbol $X$ (used later in the text) implies that the relevant gene can be represented by any possible allele.

\section{Materials}

The 883 accessions of cultivated pea subspecies (Pisum sativum sp. sativum L., P. s. ssp. asiaticum Govorov, and $P$. s. ssp. transcaucasicum (Govorov) Makasheva, from the V.I.R. (Vavilov All-Union Institute of 


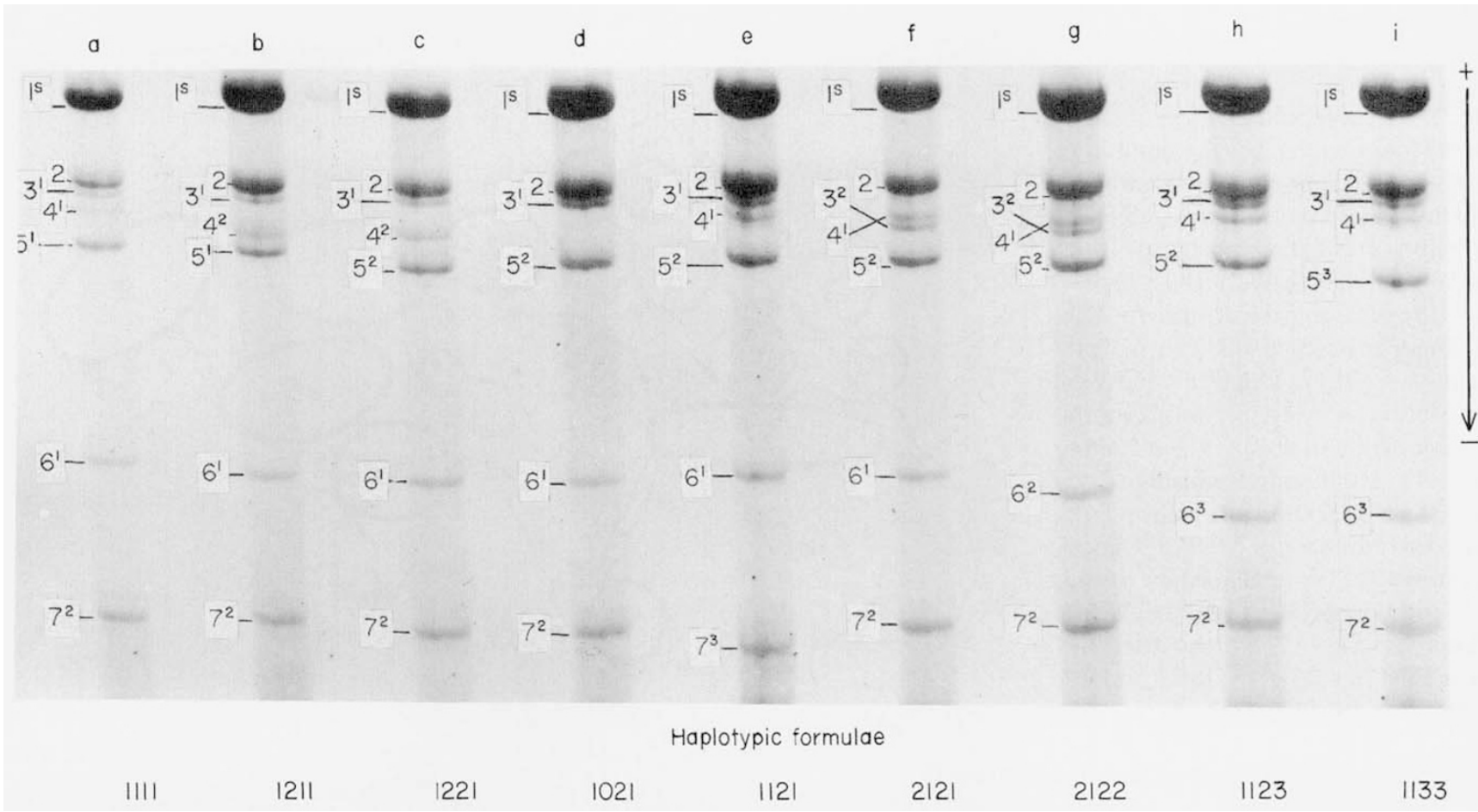

Fig. 1. Electrophoretic composition of pea (Pisum sativum L.) histone H1: examples of the most frequent haplotypes. Figures denote $\mathrm{H} 1$ subtypes; superscripts, allelic variants. (Note that allelic variant 2 of subtype 3 is faster than variant 1 of subtype 4.) $1^{\mathrm{s}}$ denotes the 'slow' variants of subtype 1. (a) V.I.R.-2303, Arkhangelsk region; (b) V.I.R.-5742, Bulgaria; (c) V.I.R.-4204, Finland; (d) V.I.R.-3716, Arkhangelsk region; (e) V.I.R.-4473, Serbia; (f) V.I.R.-4391, Daghestan; (g) V.I.R.-4993, Daghestan; (h) V.I.R.4010, Greece; (i) V.I.R.-6350, Afghanistan.

Plant Breeding, Leningrad)) collection were analysed. For our analysis we tried to choose local forms not affected by systematic selection. First, we took aboriginal peas collected by N. I. Vavilov and his colleagues (mostly before 1929) during numerous expeditions into regions with primitive agriculture. Also, our samples were supplemented with pea landraces traditionally used by local farmers, represented in the V.I.R. collection by accessions with precisely specified geographic origin. Extensively used cultivars were not included in the study.

The chosen accessions were attributed to 19 regions of the Old World (Fig. 2), so that each region included not less than 30 accessions. The majority of accessions was homogeneous for the $\mathrm{H} 1$ pattern, although some of them contained several patterns. Each accession was represented in regional samples by two plants.

A number of accessions of Pisum sativum wild subspecies, namely $P$. s. ssp. syriacum (Boiss. et Noë) Berger $(=P$. s. ssp. humile Boiss. et Noë), and P. s. sp. elatius (Bieb.) Schmalh., and a wild pea species Pisum fulvum Sibth. et Smith, from the V.I.R. collection, as well as some other sources, were also analysed. These data are not included in regional samples. We also excluded five accessions of a very peculiar subspecies (often considered as a distinct species) Pisum sativum sp. abyssinicum (A.Br) Berger.

\section{Results}

\section{Distribution of alleles of subtype 1}

The great majority of peas examined possess the same, 'slow', allelic variant of the subtype 1 . The 'fast' allelic variant of this subtype has been observed only in eight regions, belonging mainly to the subtropical climatic zone (Fig. 3). These are Southern Europe, Asia Minor, the Caucasus, Afghanistan, Tadjikistan, India, China and Ethiopia. The maximal occurrence of the fast allele is attributed to the vicinity of the 38th parallel (not shown); we failed to observe this variant to the north of the 44th parallel. It is highly improbable that this event is accidental $(P<0.001)$. Besides, we found the third 'superslow' allele of subtype 1 four times: in two accessions from Georgia, one accession from Spain, and in a very heterogenic accession V.I.R.320 of P. s. syriacum from Palestine. 
Fig. 2. An accepted division of the Old World into regions. $n$ is the number of accessions examined. (1) Finland and North-Western part of the U.S.S.R. $(n=38)$; (2) North Dvina basin $(n=34)$; (3) North-Western Europe $(n=38) ;(4)$ Central Europe $(n=32)$; (5) Dnieper basin $(n=31)$; (6) Volga basin $(n=30) ;(7)$ The Urals and Western Siberia $(n=34)$; (8) South Siberia and Mongolia $(n=40) ;(9)$ Far East $(n=34) ;(10)$ Iberian Peninsula $(n=38) ;(11)$ South Europe $(n=54)$; (12) Asia Minor $(n=78)$; (13) Caucasus $(n=43) ;(14)$ Afghanistan $(n=48)$; (15) Tadjikistan $(n=114)$; (16) Western China $(n=51) ;(17)$ North Africa and Near East $(n=33) ;(18)$ India and $\operatorname{Nepal}(n=40) ;(19)$ Ethiopia $(n=65)$.

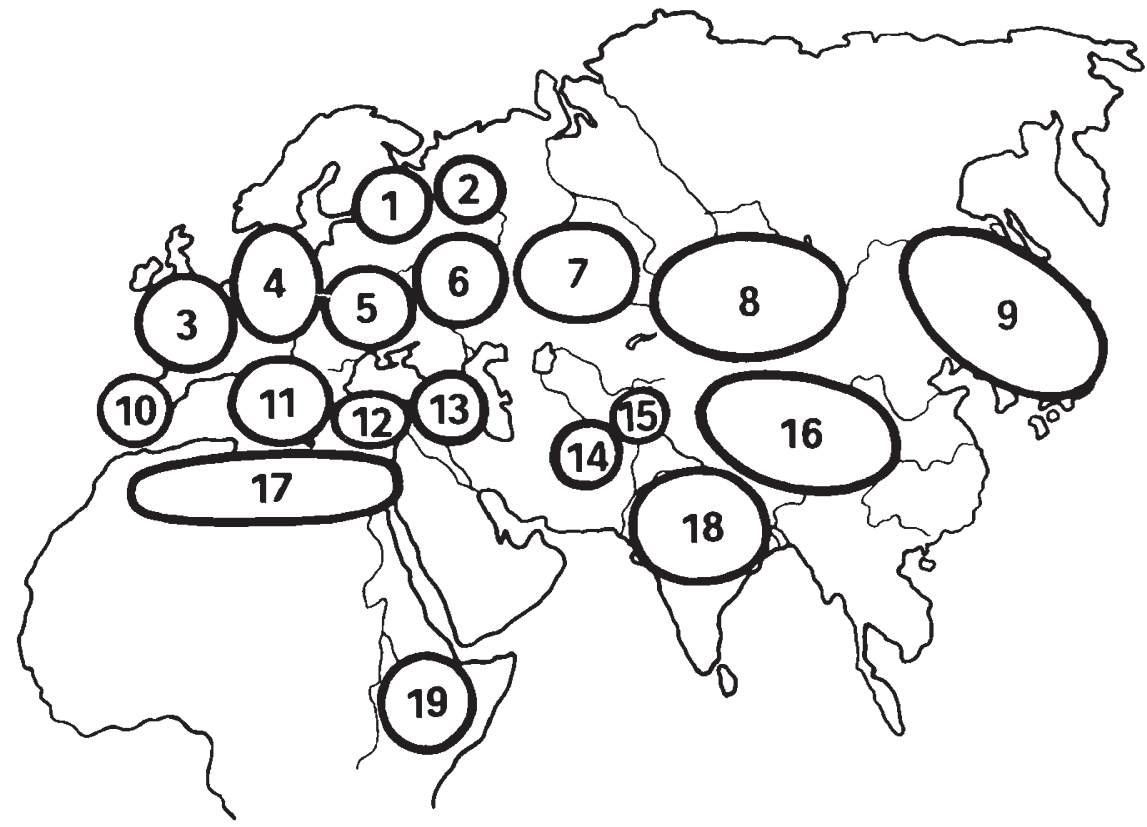

Fig. 3. Geographic distribution of the frequencies of the fast variant of subtype 1 .

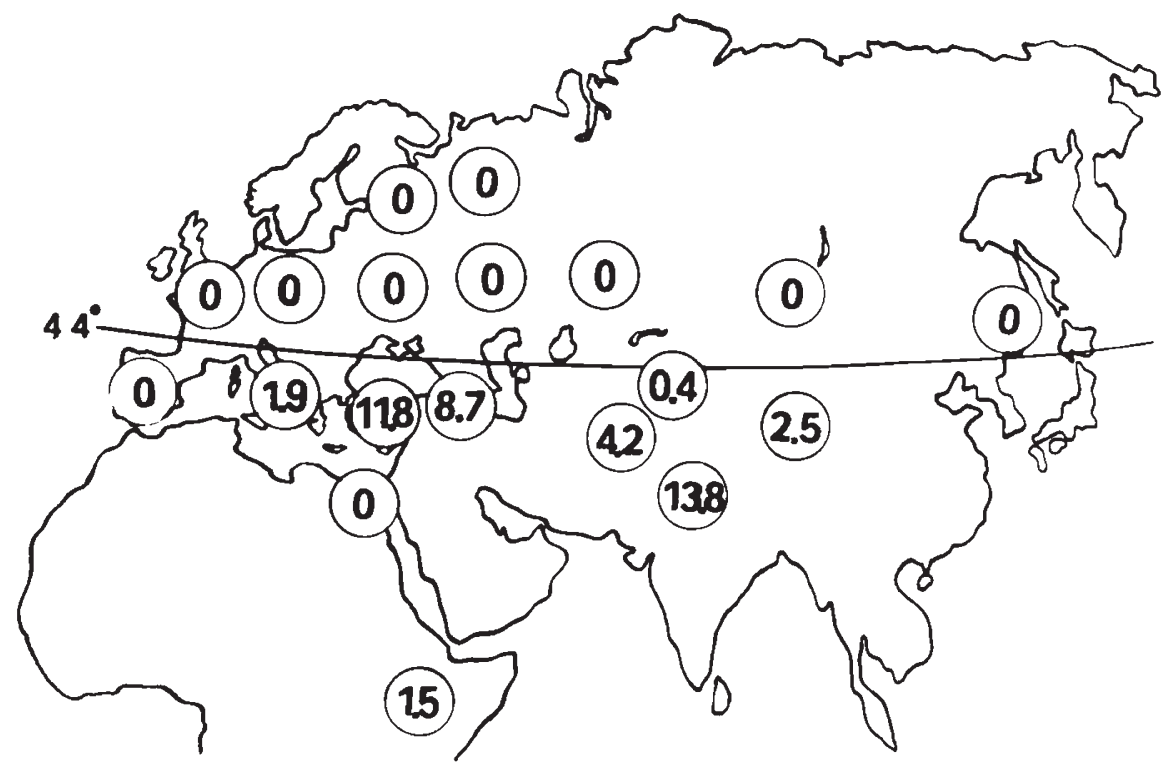

\section{Variants of subtype 2}

Nine accessions originating from different countries (one from Holland, one from Russia (Perm region), one from Tadjikistan, one from Afghanistan, one from China, one from Morocco, two from Ethiopia) turned out to have a slightly slower electrophoretic variant than subtype 2, one accession from China had a variant with a slightly increased mobility, and all the others had the same common variant.

\section{Distribution of haplotypes of subtypes 3-6}

Tables 1 and 2 show the occurrence of different haplotypes of subtypes 3-6 in the regional samples

examined. We observed a total of 33 haplotypes. Some of them are common in every regional sample (Table 1 ): the most frequent of these are 1121, 1221, 1021 and, to some extent, 2121, whereas others are rare (Table 2). For simplicity we considered the distribution of the allelic frequencies of each subtype independently, bearing in mind the constraints exerted by linkage disequilibrium.

\section{Geographic pattern of alleles of subtype 6}

Allele 1, encoding the slowest electrophoretic variant of subtype 6 , was found to predominate in all regions examined except for three Asian regions, where it was 
Table 1 Occurrence of frequent haplotypes of histone $\mathrm{H} 1$ fast subtypes in examined regions

\begin{tabular}{|c|c|c|c|c|c|c|c|c|c|c|c|c|c|c|c|c|c|c|c|}
\hline \multirow[b]{2}{*}{ Haplotypes } & \multicolumn{19}{|c|}{ Regions } \\
\hline & 1 & 2 & 3 & 4 & 5 & 6 & 7 & 8 & 9 & 10 & 11 & 12 & 13 & 14 & 15 & 16 & 17 & 18 & 19 \\
\hline 1111 & 13 & 14 & 4 & 10 & 6 & 4 & 4 & 8 & 0 & 0 & 0 & 0 & 4 & 6 & 6 & 0 & 6 & 0 & 4 \\
\hline 1121 & 21 & 24 & 28 & 36 & 13 & 25 & 32 & 48 & 32 & 69 & 40 & 130 & 24 & 21 & 49 & 16 & 24 & 30 & 27 \\
\hline 1131 & 2 & 2 & 0 & 0 & 2 & 0 & 2 & 0 & 0 & 4 & 0 & 16 & 0 & 2 & 0 & 0 & 0 & 0 & 2 \\
\hline 1211 & 28 & 18 & 2 & 10 & 12 & 14 & 35 & 8 & 6 & 6 & 10 & 0 & 7 & 2 & 56 & 2 & 2 & 2 & 6 \\
\hline 1221 & 26 & 14 & 48 & 36 & 24 & 26 & 33 & 38 & 26 & 30 & 70 & 82 & 41 & 18 & 36 & 18 & 66 & 50 & 161 \\
\hline 1231 & 0 & 0 & 0 & 0 & 4 & 6 & 1 & 4 & 12 & 12 & 4 & 4 & 0 & 0 & 2 & 0 & 0 & 4 & 0 \\
\hline 1011 & 0 & 0 & 14 & 4 & 2 & 0 & 0 & 2 & 0 & 0 & 3 & 0 & 0 & 0 & 2 & 0 & 0 & 0 & 6 \\
\hline 1021 & 52 & 50 & 46 & 20 & 34 & 18 & 34 & 14 & 50 & 16 & 48 & 56 & 12 & 17 & 36 & 12 & 14 & 28 & 16 \\
\hline 2121 & 0 & 4 & 6 & 0 & 8 & 0 & 0 & 3 & 0 & 11 & 8 & 10 & 32 & 8 & 8 & 4 & 16 & 0 & 38 \\
\hline 1123 & 0 & 4 & 4 & 0 & 13 & 17 & 10 & 24 & 6 & 4 & 8 & 12 & 4 & 68 & 145 & 112 & 0 & 40 & 0 \\
\hline 1133 & 0 & 0 & 0 & 0 & 0 & 4 & 4 & 4 & 0 & 0 & 0 & 0 & 2 & 31 & 50 & 15 & 0 & 0 & 0 \\
\hline 1013 & 0 & 0 & 0 & 4 & 0 & 6 & 6 & 0 & 0 & 0 & 1 & 0 & 0 & 3 & 2 & 9 & 0 & 0 & 0 \\
\hline 1023 & 0 & 0 & 0 & 0 & 0 & 0 & 0 & 0 & 0 & 0 & 2 & 0 & 0 & 9 & 4 & 11 & 0 & 0 & 0 \\
\hline 2122 & 0 & 0 & 0 & 4 & 0 & 0 & 0 & 4 & 0 & 0 & 0 & 0 & 32 & 0 & 28 & 0 & 0 & 6 & 0 \\
\hline$N$ & 152 & 136 & 152 & 128 & 124 & 120 & 168 & 160 & 136 & 152 & 216 & 312 & 172 & 192 & 456 & 204 & 132 & 160 & 260 \\
\hline
\end{tabular}

Regions are numbered as in Fig. 2.

$N$ is the total number of examined chromosomes, i.e. the twofold number of plants, or the fourfold number of accessions.

replaced with allele 3 . Regional frequencies of allele 3 (Fig. 4) form an evident cline with the maximum in Central Asia.

As these alleles belong to certain haplotypes, we consider all haplotypes carrying the same allele of subtype 6 as a haplotypic group. Table 3 (see also Fig. 7) gives proportions of the main haplotypes within $\mathrm{XXX} 3$ group for regions where they are frequent; there is an extremely high proportion of haplotype 1123 . At the same time, the XXX1 group has no haplotype that predominates anywhere (Table 4).

In the Caucasus we observed a high frequency $(19.8$ per cent) of allele 2 of subtype 6 , although it was extremely rare in other regions (Tables 1 and 2). This allele appears almost exclusively in haplotype 2122 . The fourth allele of subtype 6 was seen in two accessions from Greece, one from the Minsk region, and one from the Irkutsk region.

\section{Geographic pattern of alleles of subtype 5}

We distinguished three electrophoretic variants of subtype 5. (Variant 2 is represented by one of two forms with hardly detectable differences in electrophoretic mobility: less than 0.5 per cent.) Figure 5 demonstrates the geographic distribution of their frequencies. Note that there is a clear trend for allele 1 frequency to increase in the northern direction. The trend is disrupted only in Tadjikistan because of the high fre- quency of haplotype 1211 . We found that more than half of the specimens having this haplotype were attributed to a narrow region of Gorny Badakhshan. This alpine region of the Pamirs is characterized by a severe climate, similar to that of the northern boundary of agriculture.

The similarity is well reflected by the sum of aerial temperatures over the vegetational period with temperatures above $10^{\circ} \mathrm{C}$ (Agricultural Atlas of the World, 1972). In Fig. 6a frequencies of allele 1 of subtype 5 are plotted against this temperature sum (the sample from Tadjikistan being replaced by the sample from Gorny Badakhshan). This frequency decreases rapidly with the increase in the sum of vegetational temperatures. A logarithmic transformation of the axis of temperature sums linearizes this relationship (Fig. $6 \mathrm{~b})$, the correlation coefficient being -0.84 $(P<0.005)$. It should be noted that the trend becomes more explicit (correlation coefficient -0.91 ) if we consider the proportion of XX11 haplotypes within haplotypic group XXX1.

\section{Alleles of subtypes 3 and 4}

There are two points of interest concerning these subtypes. First, no pea plant was found to possess the allelic combination $22 \mathrm{XX}$. Second, the null allele of subtype 4 is often observed, while the null alleles of other subtypes are scarce. Figure 7 shows the 


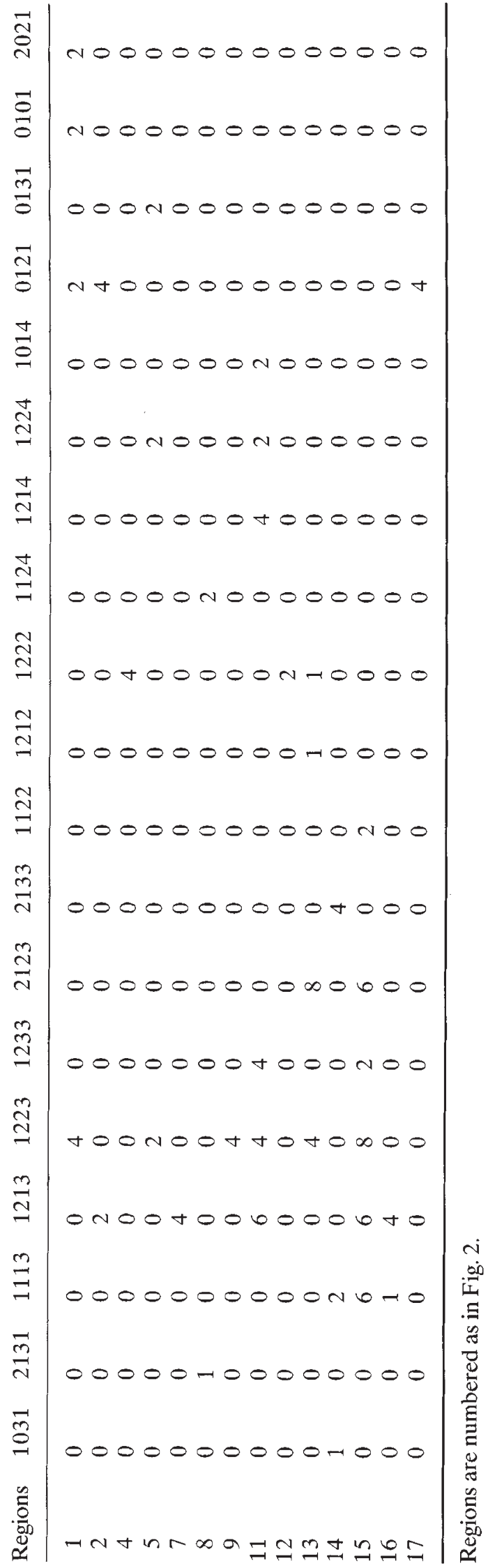

geographical distribution of the frequencies of classes which combine haplotypes with certain alleles of subtypes 3, 4 and 6 and any allele of the above-considered subtype 5. No clear trend concerning alleles of subtypes 3 and 4 is observed, although one can note an increase in the 10X1 frequency in some northern regions and in the frequency of $12 \mathrm{X} 1$ in both African regions. Also, a high frequency of 2122 haplotypes is typical for the Caucasus (Table 1).

\section{Histone $\mathrm{H} 1$ of wild pea forms}

We observed a considerable variation in the $\mathrm{H} 1$ pattern of wild pea forms. Among seven studied accessions of $P$. s. syriacum $(=P$. s. humile), three from Turkey possess haplotype 1121, four from Palestine have haplotypes 1223, 1123, 1423, and 1031 and 1021 in the same accession. All of them have the slow variant of subtype 1, and one Palestinian accession also possesses the 'superslow' variant.

Accessions of $P$. s. elatius have the slow variant of subtype 1 and haplotypes 1121 (two accessions, Italy and Georgia), 1211 (two, Palestine and Armenia), 1223 (one, Palestine), 1123 (two, Crimea), 2121 (one, Turkey), 2122 (one, Georgia).

All five studied accessions of $P$. s. abyssinicum have the same H1 spectrum: the slow variant of subtype 1 , the slower variant of subtype 2 , and haplotype $121 * 3$ (where variant $1^{*}$ of subtype 5 is slightly faster than variant 1 ).

Five accessions of a wild species Pisum fulvum, originating from Palestine, contain $\mathrm{H} 1$ variants that were not found in Pisum sativum: the variant 3 of subtype 4 , and the variant $1^{\prime}$ of subtype 3 , that is slightly slower than variant 1 . Thus, the observed haplotypes are $1323,1^{\prime} 333$ and 1333 (two accessions). Also, two accessions contain the fast allele of subtype 1 , three the slow one.

\section{Discussion}

\section{Cultivated plants as a model for the study of evolution}

Aboriginal forms of cultivated plants provide a number of advantages for the study of microevolution. First, up to the beginning of conscious selection, cultivated plants taken by a primitive farmer to new environments were undergoing natural selection by various factors such as different climates, soil types, varying altitudes, the day length, pest pressure, etc. Artificial selection consisted only in favouring a yield increase that coincided with the 'aim' of natural selection, i.e. an increased fitness. 


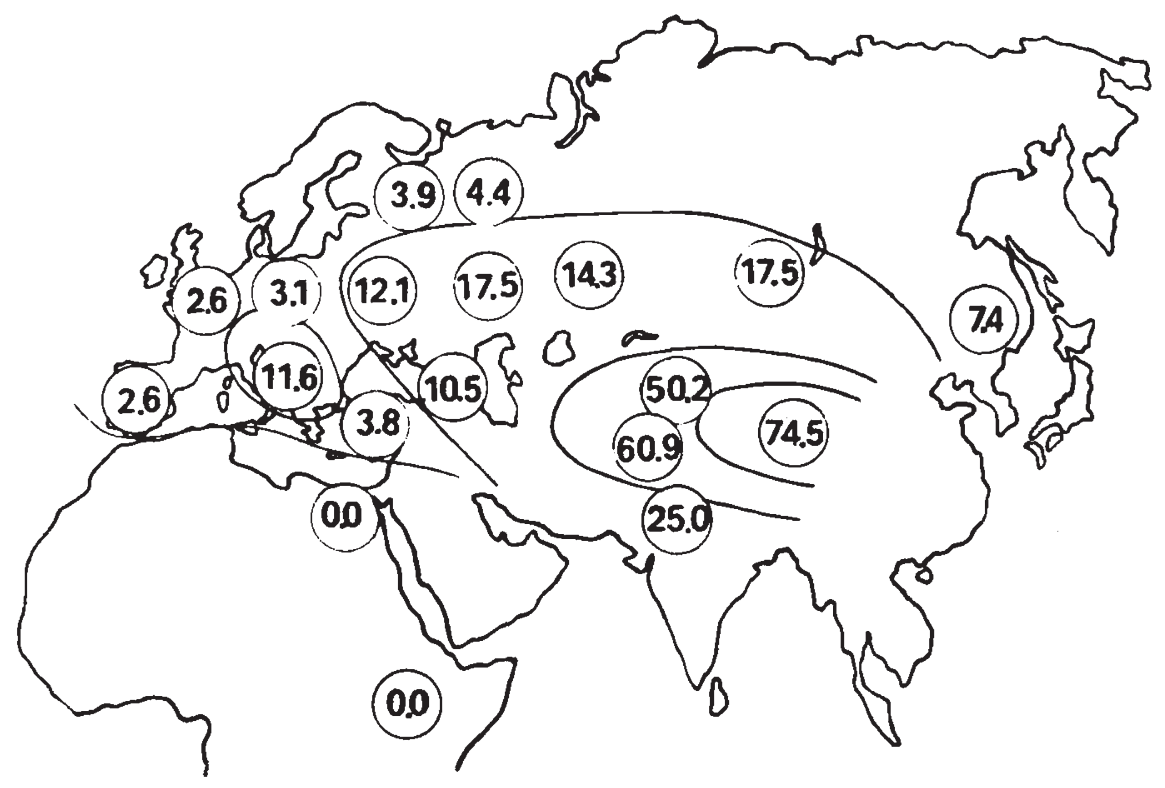

Fig. 4. Geographic distribution of the frequencies of allele 3 of $\mathrm{H} 1$ subtype 6 .

Table 3 Proportion of histone H1 haplotypes within XXX3 haplotypic group for samples from Central Asian regions and other regions combined

\begin{tabular}{llrllllllllllll}
\hline \multicolumn{10}{l}{ Haplotypes $(\%)$} \\
\cline { 2 - 13 } Samples & 1123 & 1133 & 1013 & 1023 & 1223 & 1213 & 2123 & 1113 & 1233 & 2133 & 0103 & $n_{\dagger}^{\dagger}$ & $N \ddagger$ \\
\hline Afghanistan & 58.1 & 26.5 & 2.6 & 7.7 & 0.0 & 0.0 & 0.0 & 1.7 & 0.0 & 3.4 & 0.0 & 117 & 192 \\
Tadjikistan & 63.3 & 21.8 & 0.9 & 1.7 & 3.5 & 2.6 & 2.6 & 2.6 & 0.8 & 0.0 & 0.0 & 229 & 456 \\
China & 73.3 & 9.9 & 5.9 & 7.2 & 0.0 & 2.6 & 0.0 & 0.7 & 0.0 & 0.0 & 0.0 & 152 & 204 \\
Other regions combined & 65.5 & 6.3 & 7.6 & 0.9 & 8.1 & 5.4 & 3.6 & 0.0 & 1.8 & 0.0 & 0.9 & 223 & 2678 \\
Total sample & 65.3 & 15.2 & 4.3 & 3.6 & 3.6 & 3.1 & 1.9 & 1.2 & 0.8 & 0.5 & 0.3 & 721 & 3530 \\
\hline
\end{tabular}

t $n$ is the number of chromosomes with XXX3 haplotypes.

$\ddagger N$ is the total number of chromosomes (the fourfold number of accessions) examined.

Table 4 Proportion of the most frequent histone $\mathrm{H} 1$ haplotypes within XXX1 haplotypic group for combined samples corresponding to major parts of the Old World

\begin{tabular}{lrrrrrrrrrrrr}
\hline \multicolumn{1}{l}{} & \multicolumn{1}{l}{ Haplotypes $(\%)$} \\
\cline { 2 - 12 } Samples & 1221 & 1021 & 1121 & 2121 & 1211 & 1011 & 1111 & 1231 & 1131 & $n \dagger$ & $N \ddagger$ \\
\hline West Europe $^{1}$ & 30.9 & 21.8 & 29.1 & 4.2 & 4.7 & 3.5 & 2.4 & 2.7 & 0.7 & 595 & 648 \\
East Europe $^{2}$ & 19.9 & 30.4 & 18.6 & 1.9 & 17.3 & 0.3 & 6.6 & 1.8 & 1.8 & 618 & 700 \\
North-East Asia $^{3}$ & 25.5 & 25.5 & 31.9 & 1.2 & 5.6 & 0.8 & 3.2 & 6.4 & 0.0 & 251 & 296 \\
Central Asia $^{4}$ & 22.4 & 20.2 & 26.7 & 6.2 & 18.6 & 0.6 & 3.7 & 0.6 & 0.6 & 322 & 852 \\
India $^{5}$ & 43.9 & 24.6 & 26.3 & 0.0 & 1.8 & 0.0 & 0.0 & 3.5 & 0.0 & 114 & 160 \\
Anterior Asia and North Africa $^{6}$ & 33.8 & 16.4 & 31.8 & 10.8 & 1.6 & 0.0 & 1.8 & 0.7 & 2.9 & 560 & 616 \\
Ethiopia $^{7}$ & 61.9 & 6.2 & 10.4 & 14.6 & 2.3 & 2.3 & 1.5 & 0.0 & 0.8 & 260 & 260 \\
Total sample & 31.1 & 21.1 & 25.4 & 5.8 & 8.3 & 1.2 & 3.3 & 2.0 & 1.3 & 2731 & 3530 \\
\hline
\end{tabular}

Regions are numbered as in Fig. 2.

${ }^{1}$ Region no. $3,4,10,11 ;{ }^{2}$ region no. $1,2,5,6,7 ;{ }^{3}$ region no. 8,$9 ;{ }^{4}$ region no. $14,15,16 ;{ }^{5}$ region no. $18 ;{ }^{6}$ region no. $12,13,17$;

${ }^{7}$ region no. 19.

$t n$ is the number of chromosomes with XXX1 haplotypes.

$\ddagger N$ is the total number of chromosomes (the fourfold number of accessions) examined. 
Fig. 5. Geographic distribution of the frequencies of allele 1 of $\mathrm{H} 1$ subtype 5 .

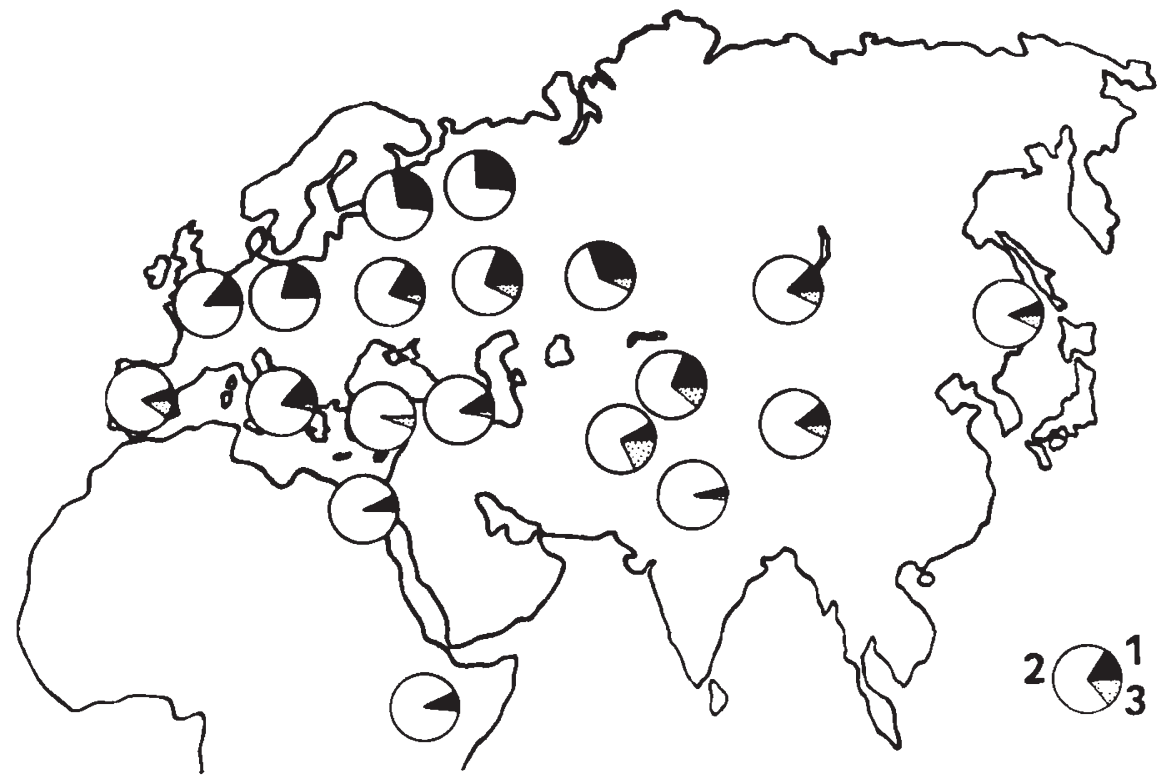

Second, evolution of cultivated plant species under the pressure of natural selection should be accelerated compared with that of wild counterparts because of the more homogenous conditions provided by synchronous sowing and other techniques, leading to a decrease of environmental components in the phenotypic variance and hence to the better exposure for the selective advantages of certain genotypes. Moreover, population sizes of cultivated plants are large enough for the effect of genetic drift to be neglected. For example, the seed stock needed for sowing the field typical for Highland Pamirs (Vavilov \& Bukinitsh, 1959) should be not less than $10^{5}$.

Third, there is often archaeological and historical information available concerning the region, and the time of domestication and history of a cultivated plant. Finally, cultivated species have often been genetically well studied.

\section{Evolution of cultivated pea and its H1 composition}

A complex of archaeological, botanical and genetic data shows that the pea, together with barley, wheats and lentil, was among the first domesticated plants. The domestication event, coinciding with the 'Neolithic transition' to productive farming, occurred approximately 10,000 years ago presumably in the region of the so-called Tauro-Zagros Arc (Ammerman \& Cavalli-Sforza, 1984). Zohary and Hopf (Zohary \& Hopf, 1973; Hopf, 1986) assume the Anatolian subspecies P.s. syriacum to be an ancestor of the cultivated pea, P.s. sativum. Radial migration of Neolithic farmers and their culture from this centre with a mean rate of approximately $1 \mathrm{~km}$ per year (Ammerman \& CavalliSforza, 1984), was followed by cultivated plants expanding over a constantly widening area. This migration was followed by genetic differentiation of cultivated species. The process lasted for several thousand years of farming, during which time the agrotechnical level was extremely low and the exchange of seeds between distant regions was probably non-significant.

Some regional forms of pea, formed in the course of its expansion over the Old World, achieved a subspecies taxonomic rank (Govorov, 1937; Makasheva, 1979). Subspecies P.s. asiaticum, characterized by early ripening and resistance to late frost, was isolated from Asia, except its Boreal part, and probably was formed in the Central Asian highlands. Subspecies P.s. transcaucasicum, a peculiar form with narrow leaflets and very small seeds, is common in the Caucasus, where it is used as a fodder crop.

The ancestral genetic pool of the domesticated pea probably contained haplotypes $1121,1221,1021$ and 2121 , which still predominate in peas all over the world except Central Asia and China (Table 4). Two of these haplotypes, 1121 and 1021 , were found in the examined specimens of P.s. syriacum - the putative ancestor of the cultivated pea.

It should be noted here that an allele of any $\mathrm{H} 1$ gene, once arisen by mutation, can hardly be transferred to other haplotypes by cross-over, because of the close linkage between genes of H1 subtypes 2-6, and because the pea is a self-pollinator. (Rather common cross-pollination is reported only for peas from Afghani- 


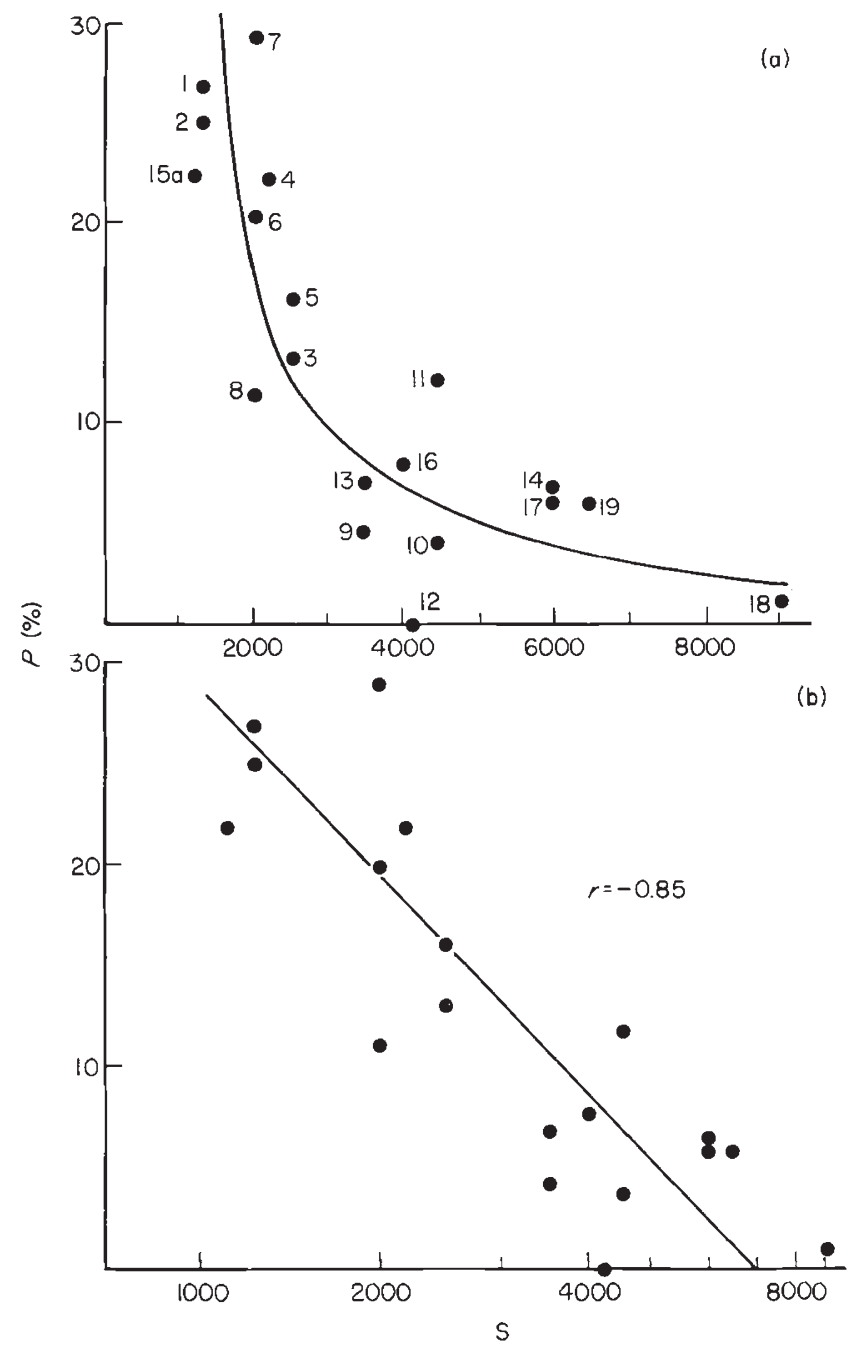

Fig. 6. Frequencies (p) of allele 1 of $\mathrm{H} 1$ subtype 5 plotted against the sum of aerial temperatures above $+10^{\circ}(\mathrm{S})$ (Agroclimatic Atlas of the World, 1972) for examined regions. (a) Non-transformed scales, (b) scale of S is logarithmically transformed. Numbers correspond to those of Fig. 2. The sample of Tadjikistan was replaced with that of Gorny Badakhshan (no. 15a) when calculating the correlation coefficients.

stan (Govorov, 1928). We also found that the substantial part of Afghani and Tadjik specimens still display heterozygosity for histone $\mathrm{H} 1$ haplotypes.)

In this respect a possible role of repeated mutations should not be neglected. Histone $\mathrm{H} 1$ genes contain a series of imperfect repeats encoding short amino acid sequences of five to six residues (Von Holt et al., 1979; Wells \& McBride, 1989). They could promote intragenic deletions and duplications as a result of slippage mispairing (Dover, 1989), or unequal crossover (Smith, 1976). Thus, histone $\mathrm{H} 1$ genes might have an increased rate of mutations that alters the length of the $\mathrm{H} 1$ mole- cule for a fixed segment. Such length alterations resulting in changes of electrophoretic mobility are possibly responsible for repeated appearances of the same allelic variants. A scheme of mutational transitions can be suggested for the four above mentioned haplotypes:

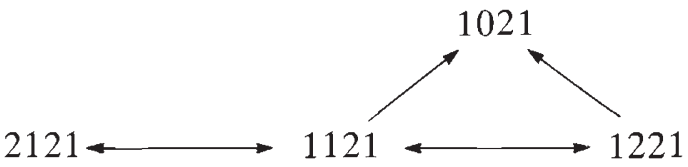

The null allele of subtype 4 can result from a loss-offunction mutation.

Among three Central Asian regions rich in XXX3 haplotypes, we found an extremely large proportion of haplotype 1123 (Table 3, Fig. 7). This can be easily explained by founder effect if one assumes the mutational transition of haplotype 1121 into 1123 to give rise to all the diversity of $\mathrm{XXX} 3$ group, where haplotypic frequencies are still far from equilibrium. This mutation was probably fixed in some isolated population, which might be ancestral for subspecies asiaticum distributed in this region. Most likely it happened when a primitive farmer carried the pea to the territory of Afghanistan. The derivatives of this population subsequently occupied an extended region of mountainous Central Asia and later penetrated into China which was devoid of this culture until the first century B.C. (Makasheva, 1979). Moderate latitudes from the Dnieper to the Yenissei were settled both by the peoples of Europe and of Central Asia. These migrational flows in their interaction could form the observed smooth gradient of XXX3 haplotypes declining in the western direction. (The tendency of the Asiatic subspecies to cross-pollination can account for the penetration of these haplotypes in other pea subspecies.)

It is intriguing that the distribution of another cultivated pea subspecies, P.s. transcaucasicum, coincides with a high concentration of haplotype 2122 . Notably, we found this haplotype in one of three examined Transcaucasian accessions of wild subspecies P.s. elatius. This wild pea could hardly have been an ancestor of the cultivated P.s. transcaucasicum. It seems more likely that the latter originated from some form of P.s. sativum, and haplotype 2122 arose from the 2121 by mutation. Later it could penetrate into a local P.s. elatius population.

Thus, we face a coincidence of the territorial distribution of cultivated pea subspecies with the high frequencies of alleles of $\mathrm{H} 1$ subtype 6 . Of course, there is no evidence for histone $\mathrm{H} 1$ genes participating in the taxonomic differentiation of pea. Nevertheless, it seems not to be impossible that changes of subtype 6 could 


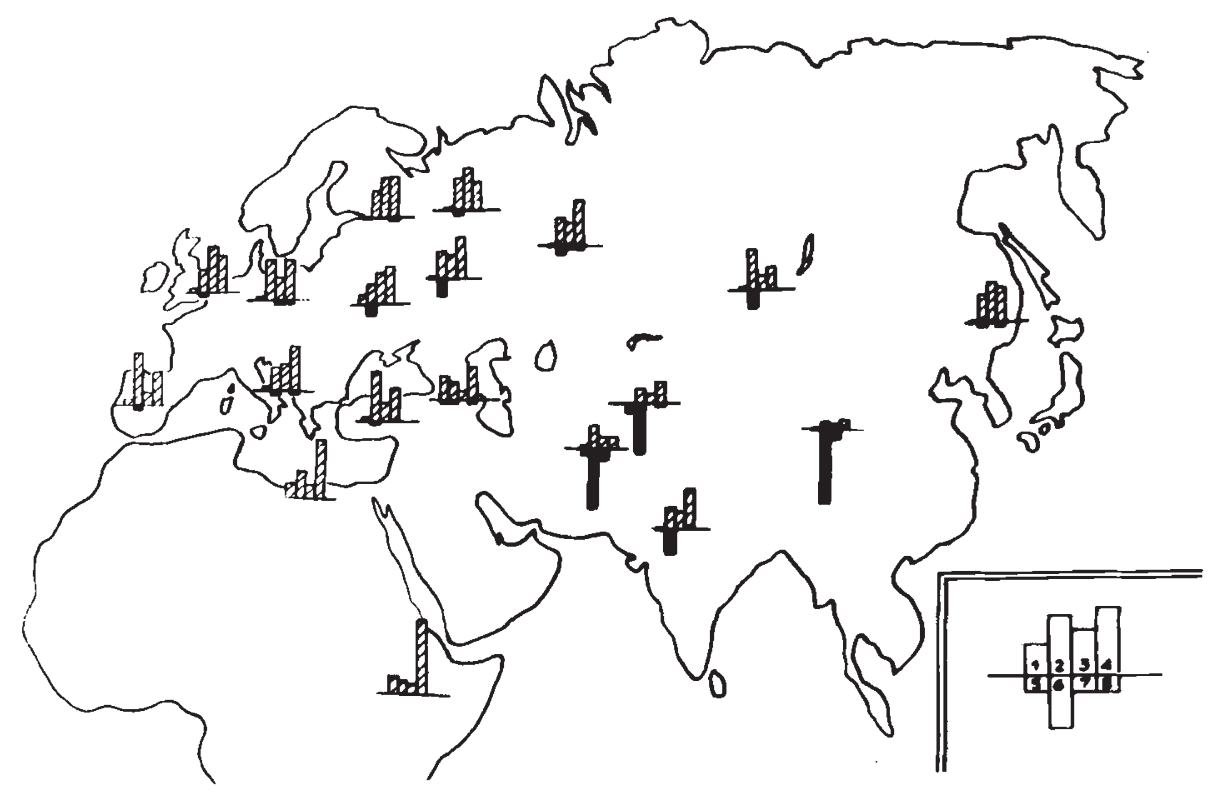

Fig. 7. Geographic distribution of the following haplotypic classes: (1) $21 \mathrm{X} 1$; (2) $11 \times 1$; (3) $10 \times 1$; (4) $12 \times 1$; (5) $21 \times 3$; (6) $11 \times 3$; (7) 10X3; (8) $12 \times 3$. The length of columns corresponds to the frequencies of classes in regional samples. influence some traits undergoing selection during the formation of new subspecies.

\section{Latitudinal variation in the allelic patterns of histone H1 genes}

The observed correlation of the frequency of allele 1 of subtype 5 with the sum over the temperatures over the vegetational period is the most remarkable result of our study, as it can hardly be explained without the assumption of some climatically-dependent selective factor which is able to distinguish between the allelic variants of histone $\mathrm{H} 1$. It should be noted that only one of five closely linked genes exhibits a correlation between the allelic frequency and the climatic factor. It is difficult to suppose that any non-selective factor such as founder effect with further migration could be responsible for the observed pattern. Any event that affected the territorial distribution of pea genotypes most probably should change allelic frequencies of closely linked genes in a concerted manner.

The observed picture seems also to exclude a hitchhiking explanation, implying that the selection acted in fact on some unknown locus linked to the $\mathrm{H} 1$ haplotype. In such a case the high frequency of allele 1 of subtype 5 in the regions with a rigorous climate would be from some certain haplotype of the XX1X class, which happened to be linked with a hypothetical advantageous gene. However, this is not the case. In two northern regions the considered allele is found in two haplotypes, 1111 and 1211, with comparable frequencies, while in the Pamirs it appears in five haplotypes: $1111,1011,1013,1113$ and 1211 , the latter one substantially predominating.
The northern boundary of distribution of the fast allelic variant of subtype 1 appeared to coincide roughly with that of the natural habitat of wild forms of pea. This might indicate that to the north of the wild pea area some natural selection acted against this allele, while polymorphism of subtype 1 in subtropical environmental conditions seems merely to be tolerable.

\section{Acknowledgements}

We are grateful to R. Kh. Makasheva, K. A. Belekhova and O. I. Romanova at V.I.R., St. Petersburg, for generously supplying us with numerous pea accessions from the V.I.R. collection, and to Professor Stig Blixt and Dr Birgitte Lund at Nordic Gene Bank, Alnarp, Sweden and Dr Norman Weeden at Cornell University, NY, U.S.A., for kindly sending us some specimens of wild peas.

\section{References}

AGRicultural ATLAS OF THE WORLD. 1972. Goltsberg, I.A. and Y. V. Pokrovskaya (eds), Gidrometeoizdat, Moskow, USSR, pp. 15-30 (in Russian).

ALLAN, J., HARTMAN, P. G., CRANE-ROBINSON, C. AND AVILES, F. X. 1980. The structure of histone $\mathrm{H} 1$ and its location on chromatin. Nature, 288, 675-679.

Ammerman, A. J. AND CAVALli-sforZA, L. L. 1984. The Neolithic Transition and the Genetics of Population in Europe. Princeton University Press, Princeton, USA.

Belyaev, A. I. AND BerdNiKov, v. A. 1981. Polymorphism and location of histone $\mathrm{H} 1$ genes in pea (Pisum sativum L.). Genetika (USSR), 1 7, 498-504 (in Russian). 
BELYAEV, A. I. AND BERDNIKOV, V. A. 1985. Intraspecific polymorphism of $\mathrm{H} 1$ histone of the wild Fabaceae species. Genetika (USSR), 21, 605-613 (in Russian).

BERDNIKOV, V. A., BOGDANOVA, V. S., GOREL, F. L. AND ROZOV, S. M. 1992. Territorial distribution of histone $\mathrm{H} 1$ alleles in a population of Vicia unijuga formed after urbanization of natural habitat. Can. J. Bot., 70, 1591-1595.

BERDNIKOV, V. A. AND GOREL, F. L. 1975. A study of ratios between histone fractions. Mol. Biol. (USSR), 9, 699-705 (in Russian).

BERDNIKOV, V. A., ROZOV, S. M., KOZLOVA, S. V. AND GOREL, F. L. 1984. Variability of $\mathrm{H} 1$ histone in different taxa of insects. Zhurnal Obshchei Biologii [J. Gen. Biol.] (USSR), 45, 318-328 (in Russian).

BOGDANOVA, V. S., ROZOV, S. M. AND BERDNIKOV, v. A. 1989. Phenotypic effect of allelic substitutions in the histone $\mathrm{H} 1$ loci of garden pea Pisum sativum L. Genetika (USSR), 25, $1420-1430$.

BROWN, D. D. 1984. The role of stable complexes that repress and activate eukaryotic genes. Cell, 37, 359-356.

COLE, R. D. 1984. A minireview of microheterogeneity in $\mathrm{H} 1$ histone and its possible significance. Anal. Biochem., 136, 24-30.

DOVER, G. A. 1989. Slips, strings and species. Trends Genet., 5, $100-102$.

Govorov, L. I. 1928. Pea of Afghanistan (on a problem of the origin of cultivated pea). Bull. Appl. Bot., Genet. Plant Breeding, 19, 497-522 (in Russian).

Govorov, L. 1. 1937. Pisum Tourn. In: Wulff, E. V. (ed.), Flora of Cultivated Plants, State Agricultural Publishing Company, Moskow, Leningrad, USSR, pp. 229-236 (in Russian).

HANNON, R., BATEMAN, E., ALLAN, J., HARBORNE, N. AND GOULD, H. 1984. Control of RNA polymerase binding to chromatin by variations in linker histone composition. J. Mol. Biol., 180, 131-149.

HOPF, M. 1986. Archaeological evidence of the spread and use of some members of Leguminosae family. In: Barigozzy, C. (ed.) The Origin and Domestication of Cultivated Plants, Symposium, 25-27 November 1985, Rome, Italy, Elsevier, Amsterdam, Netherlands, pp. 35-60.

JoHNS, E. w. 1964. Studies of histones. 7. Preparative methods for histone fractions from calf thymus. Biochem. J., 92, 55-59.

MAKASHEVA, R.KH. 1979. Flora of Cultivated Plants. IV. Grain Legumes. Part 1. Pea. Kolos, Leningrad (in Russian).
MATHER, K. AND JINKS, D. L. 1982. Biometrical Genetics: The Study of Continuous Variation, 3rd edn. Chapman and Hall, London and New York.

MOHR, E., TRIESCHMANN, L. AND GROSSBACH, U. 1989. Histone H1 in two subspecies of Chironomus thummi with different genome sizes differ largely in their content of a specific $\mathrm{H} 1$ variant. Proc. Natl. Acad. Sci. U.S.A., 86, 9308-9312.

OIKARINEN, J. 1991. Histone $\mathrm{H} 1$ and the regulation of transcription by nuclear receptors. FEBS Lett., 294, 6-10.

PANYIM, S. AND CHALKLEY, R. 1969. High resolution in acrylamide gel electrophoresis of histones. Arch. Biochem. Biophys., 130, 337.

Rozov, S. M., BOGDANOVA, v. S. AND BERDNIKOV, v. A. 1986. Different chromosomal localizations of genes coding for Pisum histone H1 fractions. Genetika (USSR), 22, 2159-2166 (in Russian).

SMIRNOVA, O. G., ROZOV, S. M. AND BERDNiKov, v. A. 1990. New genes linked to $r$ and $t l$ in pea: histone $\mathrm{H} 1$ slow fraction and seed albumin K9 genes. Pisum Newslett., 21, 63-65.

SMITH, G. P. 1976. Evolution of repeated DNA sequences by unequal crossover. Science, 191, 528-535.

SHEROD, D., JOHNSON, G. AND CHALKLEY, R. 1974. Studies on the heterogeneity of lysine-rich histones in dividing cells. $J$. Biol. Chem., 249, 3923.

THOMA, F, KOLLER, T. AND KLUG, A. 1979. Involvement of histone $\mathrm{H} 1$ in the organization of the nucleosome and of the salt-dependent superstructures of chromatin. J. Cell. Biol., 83, 403-421.

VAVILov, N. I. AND Bukinitsh, D. D. 1959. Agricultural Afghanistan. In: N. I. Vavilov. Selected Works, vol. 1. USSR Academic Science Press, Moskow, Leningrad, pp. 45-405 (in Russian).

VON HOLT, C., STRICKLAND, W. M., BRANDT, W. F. AND STRICKLAND, M. s. 1979. More histone structures. FEBS Lett., 100, 201-218.

WEINTRAUB, H. 1985. Assembly and propagation of repressed and derepressed chromatin states. Cell, 42, 705-711.

WELLS, D. E. AND MCBRIDE, C. A. 1989. Comprehensive compilation and alignment of histones and histone genes. $\mathrm{NuCl}$. Acid. Res., 17 (Suppl.), r311-346.

ZLATANOVA, J. 1990. Histone $\mathrm{H} 1$ and the regulation of transcription of eukaryotic genes. Trends Biochem. Sci., 15, 273-276.

ZOHARY, D. AND HOPF, M. 1973. Domestication of pulses in Old World. Science, 182, 887-894. 